\title{
Regulation of anti-microbial autophagy by factors of the complement system
}

\author{
Christophe Viret ${ }^{1, *}$, Aurore Rozières ${ }^{1}$, Rémi Duclaux-Loras ${ }^{1}$, Gilles Boschetti ${ }^{1}$, Stéphane Nancey ${ }^{1}$ and \\ Mathias Faure ${ }^{1,2}$ \\ ${ }^{1} \mathrm{CIRI}$, Centre International de Recherche en Infectiologie, Team Autophagy Infection Immunity, Univ Lyon, Inserm U1111, Université \\ Claude Bernard Lyon 1, CNRS, UMR5308, ENS de Lyon, F-69007, Lyon, France. \\ 2 Equipe Labellisée par la Fondation pour la Recherche Médicale, FRM. \\ * Corresponding Author: \\ Christophe Viret, CIRI, INSERM U1111, CNRS UMR 5308, ENS-L, UCBL1 - 21, Avenue Tony Garnier 69365 Lyon Cedex 07, France. \\ Phone: +3343728 23 42. Fax: +334372823 77; E-mail: christophe.viret@inserm.fr
}

\begin{abstract}
The complement system is a major component of innate immunity that participates in the defense of the host against a myriad of pathogenic microorganisms. Activation of complement allows for both local inflammatory response and physical elimination of microbes through phagocytosis or lysis. The system is highly efficient and is therefore finely regulated. In addition to these well-established properties, recent works have revealed that components of the complement system can be involved in a variety of other functions including in autophagy, the conserved mechanism that allows for the targeting and degradation of cytosolic materials by the lysosomal pathway after confining them into specialized organelles called autophagosomes. Besides impacting cell death, development or metabolism, the complement factors-autophagy connection can greatly modulate the cell autonomous, antimicrobial activity of autophagy: xenophagy. Both surface receptorligand interactions and intracellular interactions are involved in the modulation of the autophagic response to intracellular microbes by complement factors. Here, we review works that relate to the recently discovered connections between factors of the complement system and the functioning of autophagy in the context of host-pathogen relationship.
\end{abstract}

doi: $10.15698 /$ mic2020.04.712

Received originally: 20.12.2019;

in revised form: 10.03.2020,

Accepted 12.03.2020,

Published 19.03.2020.

Keywords autophagy, complement, immunity, infection, bacteria, virus, homeostasis.

\begin{abstract}
Abbreviations:
ATG - autophagy-related factor; CD4 T - mature T lymphocytes of the CD4 lineage; C3aR - C3a receptor; C5aR - C5a receptor; EGF- epidermal growth factor; GAS - group A Streptococcus; GOPC - Golgi-associated PDZ and Coiled-Coil Motif containing; GTPases - guanosine triphosphate hydrolase; LC3 (MAP1LC3) - microtubuleassociated protein 1-light chain 3; Mcr macroglobulin complement-related; mTORC1 mammalian target of rapamycin complex 1; MAC membrane attack complex (C5b-9); MASP - MBLassociated serine proteases; MAVS - mitochondrial antiviral signaling; $M B L$ - mannan-binding lectin; MCP - membrane cofactor protein (CD46); MEGF10 - multiple epidermal growth factor-like domain factor 10; MeV - Measles virus; NF-KB - nuclear factor-kappa B; PI(3)P - phosphatidylinositol 3phosphate; RCA - regulators of complement activation; ULK1 - Unc51-like kinase; VPS vacuolar protein sorting.
\end{abstract}

\section{INTRODUCTION}

Macro-autophagy, or autophagy, is a highly conserved cellular process that directs cytosolic components to endolysosomal compartments for degradation and recycling. Autophagy is required for the proper adaptation of cells to changes in their microenvironment and therefore, for cell homeostasis [1, 2]. Autophagy is constantly at work under physiological conditions, it ensures the disposal of aggregated/malformed macromolecules and organelles with signs of senescence or dysfunction. The actual removal involves the encapsulation of the targeted cargo into double-membrane vesicles named autophagosomes that undergo fusion with lysosomal vesicles to form autolysosomes where the effective degradation occurs. Because autophagy greatly contributes to the maintenance of cell homeostasis, its proper functioning is crucial for all biological functions and defective autophagy necessarily translates into various pathological manifestations [3]. Autoph- 
agy was also found to be instrumental to resist intracellular invasion by many different microorganisms thus representing an important component of cell autonomous defense mechanisms. The elimination of cytosolic microbes through the autophagic pathway is referred to as xenophagy [4]. During this process, the autophagy machinery can target components of replicating microbes for degradation but also entire microorganisms such as Group A Streptococcus (GAS) or Salmonella enterica Serovar Typhimurium (S. Typhimurium) $[5,6,7]$. As viruses are, by definition, intracellular parasites, autophagy is often mobilized to oppose viral invasion/multiplication both in vitro $[8,9,10]$ and in vivo $[11,12,13]$, including during the earliest steps of virus-host cell interactions [14]. Perhaps, the strongest indication that autophagy represents a highly efficient host defense mechanism to oppose invasion by intracellular microbes is the variety of mechanisms microbes use to escape, counteract or subvert the autophagy machinery [8, 9 , 10]. Multiple factors are able to activate autophagy. Those include hypoxia, nutrient deprivation, oxidative stress, energy limitation, endoplasmic reticulum (ER)associated stress, mitochondrial dysfunction or irradiation. Signaling pathways involved in resistance to infection can also initiate autophagy. This can be the case for NF-KB pathway regulators or DNA sensors $[15,16]$. Other factors susceptible to activate autophagy include infectioninduced GTPases, E3 ubiquitin ligases of the tripartite motif protein family (TRIMs) and the exocyst complex that regulates the interaction of exocytic vacuoles with the plasma membrane $[17,18,19,20]$. Here, we review a number of recent studies that revealed an unexpected connection between components of the complement system and the functioning of the autophagy machinery. We shall see that some complement factors have the capacity to activate or modulate the autophagic response to infection by intracellular microbes.

\section{THE AUTOPHAGY PROCESS IN MAMMALS}

Macro-autophagy, thereafter referred to as autophagy, is a multistep cellular process that relies on the engagement of dozens of factors encoded by highly conserved genes (Atg). At steady state, autophagy is maintained at a basal level by mechanistic target of rapamycin complex 1 (mTORC1) whose kinase activity controls the so called ULK1 kinase complex (Unc51-like kinase (ULK1)/ATG13/ATG101/FIP200) Perturbation of mTORC1 activates the ULK1 kinase complex causing the recruitment of the class III phosphatidylinositol 3-kinase (PI3K) vacuolar protein sorting (VPS)34 factor that promotes the formation of isolation membranes through the addition of phosphatidylinositol 3-phosphate (PI(3)P) onto membrane microdomains (initiation phase). Other factors contribute to (BECLIN1, VPS15 and ATG14L assembled in the Class III PI3K Complex I), or modulate (VMP1, AMBRA1, Bif1 and RUBICON), this step that is named the initiation phase $[21,22,17]$. Through engagement of the PI(3)P-binding factor WIPI2 and the recruitment of two ubiquitin-like conjugation systems, the isolation membrane extends to become the phagophore, a step named the elongation phase: on the one hand, ATG7 and ATG10 promote the formation of the ATG5-ATG12ATG16L1 complex that is directed to the nascent phagophore via WIPI2 and on the other hand, ATG7 cooperates with ATG4B to convert the microtubule-associated protein, light chain 3 (MAP1LC3/LC3) factors into a form (LC3-I) prone to phosphatidylethanolamine (PE) addition in the presence of both the ATG3 factor and the ATG5-ATG12ATG16L1 complex, leading to production of LC3-II. LC3-II indeed serves as a marker for the presence of autophagic membranes as it gets massively integrated into the elongating isolation membrane and stably persists until the phagophore evolves into a closed double-membrane vesicle that sequesters cytosolic cargoes and constitutes the autophagosome. LC3-I/II levels can be easily probed by Western blot-coupled SDS-PAGE and engineered versions of LC3 permit the quantitative analysis of autophagic activity through the numbering of fluorescent LC3 puncta by confocal microscopy. Along with GABARAP factors, factors of the LC3 type constitute the ATG8 family of core autophagy factors. Fully constituted autophagosomes become autolysosomes by fusing with lysosomes with, in some circumstances, an intermediate fusion step with endosomes, a step referred to as maturation. Autolysosomes represent the effective site of cargo degradation due to the catalytic microenvironment brought by the lysosomal vesicles $[23,24,22,17]$. Autophagosome maturation involves multiples factors of different classes including Rab GTPases, cytosqueleton proteins, soluble $\mathrm{N}$-acetylmaleimidesensitive factor attachment protein receptors (SNARES), SYNTAXINs, membrane-tethering components of the homotypic fusion and vacuole protein sorting (HOPS) complex, endosomal sorting complexes required for transport (ESCRT) factors and the plekstrin homology domain containing adaptor PLEKHM1 [25]. The process is promoted by the BECLIN1-VPS34-VPS15-UVRAG complex (Class III PI3K complex II) and other factors including BIF-1. While autophagy is thought to be non-selective in the case of nutrient deprivation, the targeting of particular cargoes to autophagic degradation often involves the engagement of dedicated autophagy receptors that connect the cargoes to the growing phagophore by binding LC3-II via LC3interacting regions (LIRs) domains and ubiquitin/lectin tags on cargoes via distinct specialized domains. This can be the case during the autophagic targeting of damaged organelles or of intracellular bacteria. Examples of well-studied autophagy receptors include optineurin, sequestosome 1 (SQSTM1/p62), nuclear dot $52 \mathrm{KDa}$ protein (NDP52), NBR1, TRAF6-binding protein (T6BP/TAX1BP1) or NIX-BNIP3 [26, 27]. Interestingly, particular autophagy receptors (NDP52, Optineurin, TAX1BP1) are characterized by a duality of function as they are also involved in the occurrence of efficient autophagosome maturation [28, 29, 30].

\section{THE COMPLEMENT SYSTEM}

The complement system represents an important arm of the innate immune system. It is made of dozens of soluble and membrane-associated proteins that can cooperate 
very rapidly to resist infection by various pathogens including bacteria, viruses, fungi and protozoa [31]. Soluble complement factors are massively produced in the liver and released in the blood. Proteins of the complement system are germline-encoded factors that react to microbial surface and facilitate microbe disposal by specialized phagocytes or directly trigger their lysis via lethal membrane damage. Concomitantly, complement factors facilitate the recruitment of other immune cell types by initiating inflammatory reactions. The complement system also modulates adaptive immunity through regulation of follicular dendritic cells and $B$ cells for instance, contributes to the elimination/recycling of immune complexes and apoptotic cells and is instrumental for the homeostasis of multiple immune cell types $[32,33]$. A central component of the complement system is the so-called C3 factor that is produced first as the pro- $\mathrm{C} 3$ form and is then subjected to processing while progressing through the secretory pathway that ultimately releases a complex made of a $\alpha$ and a $\beta$ chain linked by a disulfide bond. Required for the activation of the complement system is the hydrolysis of circulating C3 by convertase enzymes that disrupt the thioester link leading to co-production of a short product called C3a and a larger one named $\mathrm{C} 3 \mathrm{~b}$. C3b behaves as an opsonin that gets deposited onto target surfaces though formation of an amide or ester bond between its exposed active thioester and available amino-acid or carbohydrate moieties. Once opsonized, C3b and its potential byproducts can be recognized by adequate receptors present on the surface of various phagocytic cells [34]. Unlike C3b, C3a is an anaphylatoxin. It triggers local inflammation through activation of monocytes, endothelial cells, mast cells and neutrophils. Hence, the cleavage of $\mathrm{C} 3$ by $\mathrm{C} 3$ convertases translates into both pathogen targeting for physical elimination and localized inflammation. Once initiated, complement activation gets amplified by dedicated serine proteases while remaining under the control of membrane-associated and soluble regulatory factors [31, 35, 36, 37].

The so-called alternative, classical and lectin pathway are the three pathways capable of activating the complement system in an independent manner. The converging point of these pathways is the activation of C3. The alternative pathway is highly efficient in resisting microbial invasion. Under physiological conditions, minute quantities of C3 are naturally activated through spontaneous alteration of the intramolecular thioester bond leading to production of $\mathrm{C} 3\left(\mathrm{H}_{2} \mathrm{O}\right)$, a $\mathrm{C} 3 \mathrm{~b}$ equivalent that deposits on target surface [38]. If encountering healthy host cells, $\mathrm{C} 3\left(\mathrm{H}_{2} \mathrm{O}\right)$ is classically inactivated by regulatory factors such as Factors $\mathrm{I}$ and $\mathrm{H}$. If it deposits onto abnormal cells or microbes instead, it recruits Factor $B$ to assemble the pro-convertase $\mathrm{C} 3\left(\mathrm{H}_{2} \mathrm{O}\right) \mathrm{B}$ that itself recruits Factor $\mathrm{D}$ and Factor $\mathrm{P}$ (properdin) to form the $\mathrm{C} 3$ convertase $\mathrm{C} 3\left(\mathrm{H}_{2} \mathrm{O}\right) \mathrm{Bb}$. As a consequence, regular $\mathrm{C} 3 \mathrm{~b}$ is produced that further deposits on the targeted surface and, via engagement of Factors $B, D$ and $\mathrm{P}$, produces the $\mathrm{C} 3$ convertase $\mathrm{C} 3 \mathrm{bBb}$ [39]. This amplification effect promotes the generation of large amounts of $\mathrm{C} 3 \mathrm{~b}$ and therefore maximizes the rapid opsonization of the targets. The classical pathway involves the assembly of antibody-antigen complexes. IgM, IgG3 and IgG1 are the main antibodies interacting with the globular domain of the factor $\mathrm{C} 1 \mathrm{q}$ via their Fc portion. Associated to $\mathrm{C} 1 \mathrm{q}$ are the serine proteases $\mathrm{C} 1 \mathrm{r}$ and $\mathrm{C} 1 \mathrm{~s}$. Their activation causes the cleavage of the factor $\mathrm{C} 4$ into $\mathrm{C} 4 \mathrm{a}$ and $\mathrm{C} 4 \mathrm{~b}$ with the latter binding covalently to targets in a C3b-like manner [40]. Subsequently, the factor C2 is recruited and cleaved by $\mathrm{C} 1 \mathrm{~s}$ to produce the protease $\mathrm{C} 2 \mathrm{a}$ that along with $\mathrm{C} 4 \mathrm{~b}$ generates $\mathrm{C} 4 \mathrm{~b} 2 \mathrm{a}$, the main $\mathrm{C} 3$ convertase that reduces $\mathrm{C} 3$ into $\mathrm{C} 3 a+\mathrm{C} 3 \mathrm{~b}$ within this pathway [41]. Within the lectin pathway, the $C 3$ convertase production resembles that of the classical pathway with however an early step relying on the sensing of microbial oligosaccharides by lectins and the participation of lectin-associated proteases. Among host lectins involved are the collectin-LK and the mannanbinding lectin (MBL) that recognize carbohydrates and the ficolins 1-3 that can bind to acetylated groups on sugar moieties [42, 43]. Host lectins then associate with dimers of MBL-associated serine proteases (MASP-1 and -2). Upon engagement, MASP-1 gets auto-activated and cleaves MASP-2 that itself hydrolyses both $\mathrm{C} 4$ and $\mathrm{C} 2$ favoring the production of $\mathrm{C} 4 \mathrm{~b} 2 \mathrm{a}$, the $\mathrm{C} 3$ convertase already seen in the classical pathway [44, 45, 46]. Once C3b deposits on targets, recruitment of the Factor $B$ promotes the formation of the pro-convertase $\mathrm{C} 3 \mathrm{bB}$ that is converted into $\mathrm{C} 3 \mathrm{bBb}$ by the Factor $\mathrm{D}$. C $3 \mathrm{bBb}$, the $\mathrm{C} 3$ convertase of this pathway, is the functional equivalent of the C3 convertase C4b2a that operates in both the classic and lectin pathway. Again, the neo-production of $\mathrm{C} 3 \mathrm{~b}$ further amplifies the formation of $\mathrm{C} 3 \mathrm{bBb}$. Hence, both the classical and lectin pathway of complement activation involve the sensing of particular components on the target surfaces.

The final step of the response is the step of the target lysis. In contrast to the initiation phase, this terminal phase does not vary in its modality. It is dependent on the quantity of C3b that got associated with the target surface during the initiation phase. Subsequently to $\mathrm{C} 3 \mathrm{~b}$ recruitment, the $\mathrm{C} 3$ convertases $\mathrm{C} 3 \mathrm{bBb}$ and $\mathrm{C} 4 \mathrm{~b} 2 \mathrm{a}$ catalyze the formation of the $\mathrm{C} 3 \mathrm{bBb} 3 \mathrm{~b}$ and $\mathrm{C} 4 \mathrm{~b} 2 \mathrm{a} 3 \mathrm{~b}$ complexes endowed themselves with a convertase activity that targets the C3-related factor C5 [47, 48]. In this context, C5 gets degraded into $\mathrm{C} 5 \mathrm{a}$ and $\mathrm{C5b}$ products allowing for the recruitment of the factors $\mathrm{C} 6$ to $\mathrm{C} 9$ by $\mathrm{C} 5 \mathrm{~b}$ to generate the $\mathrm{C} 5 \mathrm{~b}-9$ complex, also named the membrane attack complex (MAC), on the targeted surface [49]. While C5a promotes localized inflammation, the MAC creates pores in biological membranes leading to the death of targeted microorganisms. Through binding to $\mathrm{C} 3 \mathrm{aR}, \mathrm{C} 5 \mathrm{aR} 1$ and $\mathrm{C} 5 \mathrm{aR} 2$ receptors on host cells, the anaphylatoxins $\mathrm{C} 3 \mathrm{a}$ and $\mathrm{C} 5 \mathrm{a}$ trigger various pro-inflammatory reactions such as oxidative burst, interleukin production, chemotaxis and production of histamine and leukotrienes [50,51].

The corollary of the potent capacity of the complement system to cause microbe elimination through either internalization/degradation or MAC-mediated lysis is the requirement for a tight regulation to preamp damages to host cell/tissues. Multiple factors of the complement system are indeed directly involved in such a regulation. Collectively, they are named the regulators of complement 
activation (RCAs). RCAs can be either membrane-bound or soluble and not surprisingly, genetic alteration in RCA genes can be associated with marked pathologies [52, 53]. While the Factor $\mathrm{H}$, the $\mathrm{C} 1$ inhibitor $(\mathrm{C} 1 \mathrm{INH})$ and the $\mathrm{C} 4 \mathrm{~b}$ binding protein (C4BP) are the main soluble RCAs, the cell surface-associated RCAs include the membrane cofactor protein (MCP/CD46), the decay-accelerating factor (DAF/CD55) and the complement receptor-1 (CR1/CD35) and -2 (CR2/CD21). RCAs exert their regulatory function either through cofactor activity as illustrated by the cofactor effect CD46 exerts on the hydrolysis of the C3B/C4b opsonins by the serine protease Factor I or through decayaccelerating activity as exemplified by the dissociation of the catalytic region of the $\mathrm{C} 3 / \mathrm{C} 5$ convertases by CD55. In some instances, RCAs can mediate both effects. Thus, Factor $\mathrm{H}$ concomitantly interferes with $\mathrm{C} 3$ convertases via a decay-accelerating effect and neutralizes $\mathrm{C} 3 \mathrm{~b}$ by serving as a cofactor for its reduction to the ic $3 \mathrm{~b}$ form by Factor I. It is remarkable to note that some microbes evolved the capacity to produce factors that promote the coating of their own surface with RCAs or to release factors that harbor biochemical properties resembling those of RCAs [54].

\section{NOVEL FUNCTIONS AND ACTION SITES FOR COMPLEMENT FACTORS}

In the recent years, various observations brought support to the notion that the complement system not only contributes to immunity but is also involved in the regulation of multiple biological phenomena including mitosis, tissue/cell homeostasis, development, metabolism or tissue repair with some of such regulations being mediated by complement factors that are synthetized and secreted locally (reviewed in $[33,55])$. In addition, recent findings also revealed that complement system factors can exert some functions within cells either directly in the cytosol or, within particular intracellular vesicles $[56,57,33,55,58]$. An interesting example is the intracellular effect that complement factors $\mathrm{C} 3 \mathrm{~b}$ and $\mathrm{C} 4 \mathrm{~b}$ can mediate after endocytosis of the microbe they were adsorbed to. In epithelial cells infected with the adenovirus, C3 factors attached to the virus get into contact with cytosolic components after exit from the endocytic vacuole, is capable of activating the mitochondrial antiviral signaling (MAVS)-related pathway and ultimately causes the production of pro-inflammatory cytokines via NF-kB engagement, protein-1 (AP-1) and interferon regulatory factor (IRF)-3-5-7 activation. At the same time, $\mathrm{C} 3 \mathrm{~b}$ can also direct the virus to the proteasome for degradation [59]. Activation of NF-kB via adsorbed C3b has also been observed for $S$. Typhimurium and the astrovirus 1 and coxsackievirus B3 non-enveloped viruses. In some instances, this activating effect on the NF-kB pathway generates only marginal effects because some microbes, such as enteroviruses, harbor enzymatic activity able to hydrolyze C3 present on their surface [59]. Besides reaching the cytosol after microbe internalization, functional complement factors can be found within fibroblasts, endothelial cells, epithelial cells or T cells due to endogenous synthesis $[60,61,62,63]$. Unlike in other cells, the cleavage of intracellular C3 into C3a and C3b is mediated by the lysosomal hydrolase cathepsin- $L$ within human resting CD4 T cells. In such cells, C3a has been found to favor cell survival via tonic modulation mTOR functions after binding to the C3a receptor (C3aR) on lysosomes [57]. Subsequently to $T$ cell receptor (TCR)-mediated activation, the C3a-C3aR interaction gets relocated to the cell surface where it promotes a more stringent mTOR activation and initiates metabolic changes compatible with differentiation into effector lymphocytes [64]. Understanding the intracellular functions of complement factors now represents an expanding field of research. The notion of a "cell-intrinsic" complement system has been put forward to describe these functions and the question of whether the intracellular functions of complement may have evolved prior to extracellular functions has been raised $[63,58]$.

\section{THE HUMAN COMPLEMENT REGULATORY FACTOR CD46 RAPIDLY TRIGGERS AUTOPHAGY IN RESPONSE TO PATHOGEN SENSING}

The measles virus (MeV) is an enveloped RNA virus of the genus Morbillivirus of the Paramyxoviridae family. MeV entry into host cells requires interaction with a surface receptor. While clinical/virulent strains engage Nectin4 and CD150/SLAM to enter epithelial cells and immune cells respectively, attenuated/vaccinal strains use CD46/MCP to infect human cells [65]. CD46 is expressed on all nucleated cells and as indicated above, it acts as an important complement regulatory factor to avoid cell lysis by complement. By binding to $\mathrm{C} 3 \mathrm{~b}$ and $\mathrm{C} 4 \mathrm{~b}$ that deposit on cells, CD46 serves as a cofactor for the serine protease Factor I that hydrolyzes them leading to production of ic $3 b+$ soluble C3f and C4d + soluble C4c, respectively $[66,67]$. Vaccinal/attenuated $\mathrm{MeV}$ strains rapidly activate autophagy during epithelial cell infection. This activation is a direct consequence of its interaction with CD46 and translates into both LC3-II formation and LC3-positive puncta formation with a maximum reached $1.5 \mathrm{~h}$ after infection [68]. MeV-induced autophagic activity then normalizes by $3 \mathrm{~h}$ without the need for active inhibition. MeV infection associated autophagy is independent of viral protein synthesis as shown by its unperturbed induction in the presence of non-replicative MeV particles. The triggering of autophagy is indeed strictly related to the engagement of CD46 on the cell surface. For instance, the cross-linking of CD46 by the mean of monoclonal antibodies is sufficient to cause autophagy induction in human epithelial cells. With respect to the mechanism involved, CD46-induced autophagy relies on the engagement of the CD46-Cyt-1, but not -Cyt-2, intracytoplasmic splice variant [69] as demonstrated by the failure of vaccinal/attenuated MeV to activate autophagy in cells devoid of CD46-Cyt-1 [68]. The connection between CD46-Cyt-1 and autophagy triggering involves interaction with the class I PDZ portion of Golgi-associated PDZ and Coiled-Coil Motif containing (GOPC), a scaffold protein able to interact with the VPS34-BECLIN1 complex. Accordingly, silencing the expression of GOPC neutralizes the capacity of vaccinal/attenuated $\mathrm{MeV}$ to activate autophagy with no 
effect on the surface expression of CD46. It is worth emphasizing that the early burst of autophagy induced by CD46 engagement is strictly decoupled from the subsequent and sustained autophagic activity associated with $\mathrm{MeV}$ infection. In the latter case, autophagy is directly related to viral replication and in fact, is beneficial to the virus $[70,30]$. Consistent with the key role for CD46 in early autophagy induction by vaccinal/attenuated $\mathrm{MeV}$, virulent/clinical MeV strains that are independent of CD46 for infection do not trigger any signs of early autophagic activity, indicating that the CD46-Cyt-1-GOPC-VPS34-BECN1 complex axis constitutes the sole pathway for early autophagy induction by vaccinal/attenuated strains of $\mathrm{MeV}$ [71]. The CD46-Cyt-1-GOPC-VPS34-BECN1 complex pathway is also operating in autophagy induction during infection of human cells by GAS [68] and Neisseria gonorrhoeae [72] that both bind to CD46. As CD46 is also a receptor for various other pathogens such as the human herpes virus HHV- 6 , the BVDV pestivirus and adenoviruses $B$ and $D$, the CD46-Cyt-1-GOPC-VPS34-BECN1 complex axis is likely to also trigger autophagy during infection by those microbes [73]. Thus, the observations made with the Morbillivirus $\mathrm{MeV}$ allowed for the identification of the complement regulatory factor CD46 as a pathogen sensor endowed with the capacity to activate autophagy in cells undergoing infection (Fig.1A).

\section{THE ENGAGEMENT OF THE VSIG4 RECEPTOR BY C3b TRIGGERS AN EFFECTIVE ANTI-BACTERIAL AUTOPHAGY IN PHAGOYTIC ANTIGEN PRESENTING CELLS}

V-set and immunoglobulin domain containing 4 (VSIG4/CRIg) is a surface receptor expressed on macrophages, monocytes, and dendritic cells $[74,75]$. It is known to function as a C3b receptor involved in the efficient phagocytosis of bacteria, such as Listeria monocytogenes, coated with C3b. VSIG4 also participates in the efficient acidification of bacteria-containing vesicles through the modulation of the CLIC3 channel protein [76]. Recently, VSIG4 signaling was in fact found to also promote LC3 lipidation and structuration of LC3-positive puncta during infection of macrophage-like J774 cells by C3-coated L. monocytogenes [77]. Similar to CD46, the crosslinking of VSIG4 with specific monoclonal antibodies is sufficient to cause formation of LC3-II and puncta accumulation in THP1 or J774 macrophage-like cells. In contrast to CD46 engagement, however, the maximal level of LC3 lipidation was seen clearly latter: between 60 and $120 \mathrm{~min}$ after stimulation. Under such conditions, an increased phosphorylation of BECLIN1 was observed indicating that VSIG4 engagement alleviated BECLIN1 repression [76]. Such an autophagy induction was associated with a reduction in the level of the long-lived factor p62/SQSTM1 suggesting that the induced autophagy flux was complete. In macrophages infected with L. monocytogenes, internalized bacteria can escape phagosomes before they fuse with lysosomes by producing the phospholipase $\mathrm{C}$ and listeriolysin $\mathrm{O}$ virulence factors allowing them to access the cytosolic environment. Under conditions of VSIG4 cross-linking, L. monocytogenes could colocalize with LC3-positive punctiform structures suggesting that cytosolic bacteria were targeted by the autophagy machinery. Such a targeting was not seen when the autophagy machinery was mobilized through starvation as opposed to antibody-mediated VSIG4 engagement. Many of the bacteria that colocalized with LC3 puncta also colocalized with the lysosomal marker LAMP1, an effect that was sensitive to the autophagosome maturation blocker $\mathrm{NH}_{4} \mathrm{Cl}$, suggesting that, in cells treated with antiVSIG4 antibodies, L. monocytogenes was effectively directed to lysosomes via the autophagy machinery. When experiments were performed with THP1 macrophages devoid of the autophagy factor ATG5, L. monocytogenes was found capable of efficient proliferation with no detectable LC3 colocalization despite the antibody-mediated engagement of surface VSIG4 [77]. Of interest was the fact that VSIG4 signaling was associated with ubiquitination of cytosolic bacteria. Hence, the signaling event(s) associated with VSIG4 engagement induce an autophagic activity able to target L. monocytogenes to autophagic degradation. By using HeLa epithelial cells engineered to express VSIG4 it was observed that the lipidation of LC3 was markedly higher when cells were exposed to C3-coated L. monocytogenes as opposed to non-opsonized bacteria. In the latter situation, the level of LC3-II could be augmented by the copresence of anti-VSIG4 antibodies. Such experiments conducted with modified epithelial cells demonstrated that no contribution specific to macrophages other than VSIG4 engagement was necessary to trigger autophagy. Consistent with data obtained with macrophage-like cells, extinction of the core autophagy factor ATG5 in VSIG4-HeLa cells resulted in the lack of LC3 lipidation and augmentation of $L$. monocytogenes multiplication, further indicating that VSIG4 engagement activated anti-bacterial autophagy. The capacity of VSIG4 signaling to oppose cytosolic bacteria growth by promoting autophagy was confirmed by taking advantage of Vsig4 deficient mice. In macrophages derived from Vsig4 deficient bone-marrow progenitors, the phagocytosis of C3-opsonized L. monocytogenes was lowered, LC3 lipidation and puncta formation were impaired, the polyubiquitination of cytosolic bacteria was limited and their proliferation was enhanced. Thus, the studies with primary macrophages nicely recapitulated the key observations made in vitro by using macrophage-like cell lines. Altogether, these observations demonstrated that through the engagement of the VSIG4 receptor, C3 adsorbed on L. monocytogenes can promote an autophagic response able to restrain the cytosolic growth of bacterial cells that escape phagosomes in professional phagocytic cells (Fig.1B).

THE C3-ATG16L1 INTERACTION ACTIVIATES ANTIBACTERIAL AUTOPHAGY IN EPITHELIAL CELLS

As indicated above, once adsorbed on adenoviruses, C3 is able to activate the MAVS signaling pathways leading to secretion of pro-inflammatory factors [59]. It appears that C3 deposited on bacteria can also initiate anti-microbial defense in epithelial cells after reaching the cytosol. 
A
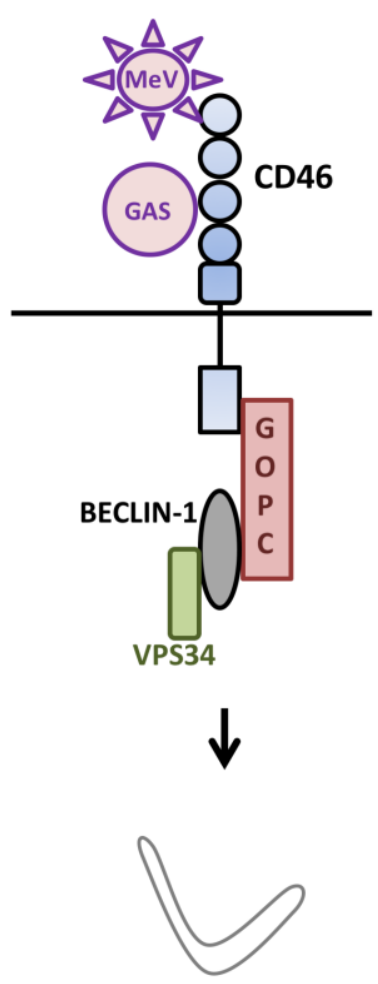

PHAGOPHORE
B
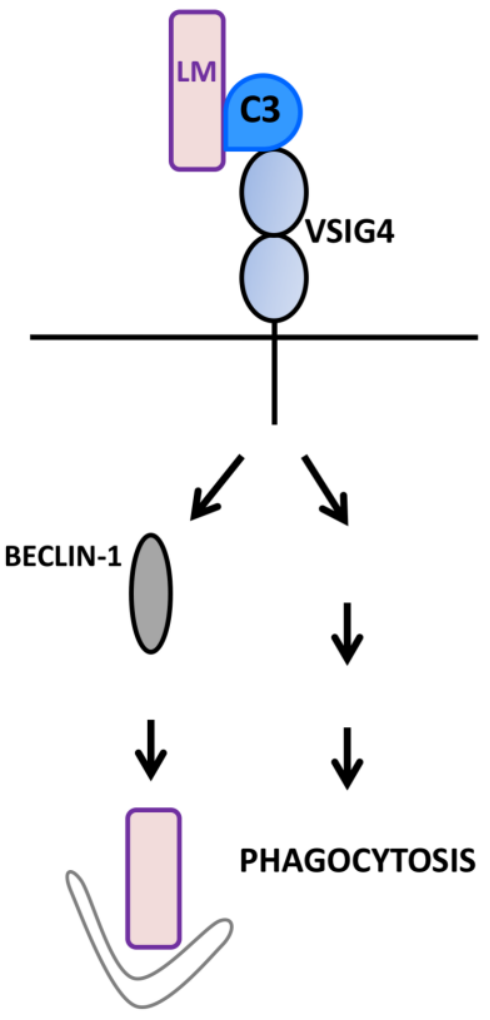

PHAGOPHORE
C

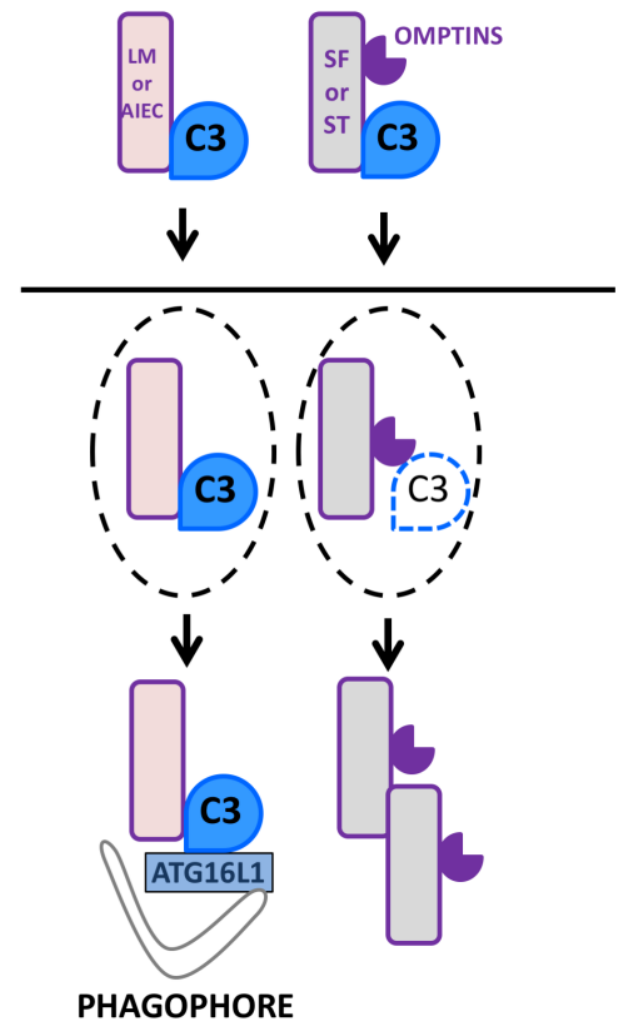

FIGURE 1: Autophagy induction by factors of the mammalian complement system in interaction with microbes. (A) Upon sensing of pathogens such as Measles virus (MeV) or group A Streptococcus (GAS), the regulator of complement activation CD46/MCP signals for autophagy induction in epithelial cells (depicted here by phagophore formation) by recruiting the BECLIN-1-VPS34 complex via the GOPC scaffold protein. (B) The macrophage surface receptor VSIG4/CRIg activates autophagy in a BECLIN-1-dependent manner in response to detection of C3 adsorbed onto L. monocytogenes (LM). Such an induction leads to the effective targeting of internalized bacteria to LC3-positive punctiform structures and then, lysosomal compartments. VSIG4/CRIg is also a positive regulator of phagocytosis in macrophages. (C) C3 deposited onto invading bacteria can induce autophagy by activating the autophagy machinery after reaching the cytosol of epithelial cells. Thus, after exiting their containing vacuole (dotted lines), C3-coated L. monocytogenes (LM) and adherent-invasive Escherichia Coli (AIEC) activate autophagy via the interaction of C3 with ATG16L1, one of the core autophagy factors. As a result, both bacteria are restricted by the induced autophagy. In contrast, other bacteria are able to escape such an antibacterial autophagy and multiply. For instance, C3-opsonized S. flexneri (SF) and S. Typhimurium (ST) are able to oppose autophagic restriction by lowering the level of the cytosolic C3-ATG16L1 interaction. This is due to their capacity to express proteolytic factors called Omptins that target C3 and reduce its amount deposited on the surface of bacterial cells.

Searching for factors able to interact with human ATG16L1, Philpott and colleagues observed and validated that the $\mathrm{C} 3$ degradation fragment $\mathrm{C} 3 \mathrm{~d}$ was among its privileged partners [78]. These authors then examined the possibility that bacteria coated with $\mathrm{C} 3$ could impact the functioning of the autophagy machinery after accessing the cytosol of host cells via the C3-ATG16L1 interaction. As expected, C3coated L. monocytogenes was more efficiently internalized by the phagocytic THP-1 cells relative to its nonmanipulated counterpart. In addition, the presence of deposited C3 was associated with a lowered capacity of the bacteria to multiply in intestinal epithelial cells. In such cells, both ATG16L1 and LC3 displayed a stronger capacity to target cytosolic C3-coated L. monocytogenes. Under such conditions, C3-coated bacteria were found to efficiently co-localize with p62 and NDP52 autophagy receptors that engage interaction with ATG8 factors, with Galectin-8 that recognizes sugar moieties on damaged bacteriacontaining vacuoles and with ubiquitin that binds to cytosolic bacterial cells, strongly suggesting that C3 opsonization of $L$. monocytogenes translated into an enhanced targeting by the autophagy machinery of epithelial cells. As a result, the resistance to the bacteria was augmented as illustrated by the C3-dependent restriction of cytosolic L. monocytogenes in ordinary epithelial cells but not in their counterpart that lacked ATG16L1. It was remarkable to observe that in complementation experiments, the autophagic restriction of C3-opsonized L. monocytogenes 
could not be restored by re-expression of the 300A variant of ATG16L1 that is associated with Crohn's disease (CD) [79]. The enhancing effect of C3 opsonization on antibacterial autophagy was indeed not restricted to L. monocytogenes as adherent-invasive Escherichia coli (AIEC), bacteria often found in expansion in patients with ileal forms of $C D$ [80] and sensitive to autophagic degradation [81], could also be restricted by autophagy in an C3- and ATG16L1-dependent manner. Hence, by engaging ATG16L1 in the cytosol of host epithelial cells, C3 adsorbed on invasive bacteria efficiently promotes their restriction by autophagy. The anti-bacterial potential of this phenomenon is best emphasized by the observation that some bacteria evolved means to oppose the C3-ATG16L1 interaction. Thus, although C3-opsonized Shigella flexneri appears well targeted by LC3 and ATG16L1 when it accesses the cytosol of epithelial cells, its expansion is indeed poorly restricted. Such an escape relies on the ability of $S$. flexneri to shed the C3 factor with a majority of bacterial cells being C3negative four hours after infection. The C3 shedding requires no contribution from host cells as it can be observed for $S$. flexneri but not L. monocytogenes, during expansion in regular media in vitro. Omptins are proteolytic factors found at the level of the outer membrane in gram-negative Enterobacteriaceae [82]. LcsP is one of such enzymes that is found in S. flexneri [83] and was therefore examined for its capacity to cause C3 shedding. S. flexneri lacking IcsP had a clearly reduced capacity to lose $\mathrm{C} 3$ in vitro and to replicate in the cytosol of host cells. This cellular restriction was dependent on C3 in ordinary, but not ATG16L1 deficient cells in agreement with the notion that IcsP does promote the elimination of C3 from S. flexneri. In the same line, the omptin PgtE expressed by S. Typhimurium and capable of cleaving C3 $[84,85]$ could promote C3 shedding by Salmonella cells: S. Typhimurium lacking PgtE inefficiently shed C3 and once C3-opsonized, became sensitive to C3dependent restriction in ordinary, but not ATG16L1 deficient cells. Hence, by catalyzing the shedding of $\mathrm{C} 3$, omptin enzymes endowed both S. Typhimurium and S. flexneri with the capacity to escape the pro-xenophagic role of deposited C3 in host epithelial cells. Interestingly, both IcsP and PtgE partially controlled the shedding of C3 suggesting that additional enzymes are likely to be involved in this process (Fig. 1C). In a mouse intra-gastric model of infection with L. monocytogenes [86], it was observed that L. monocytogenes caused the production of $\mathrm{C} 3$ in intestinal mucosa, showing that $\mathrm{C} 3$ can be in close proximity to intestinal cells in the course of infection. In contrast with lymphoid organs where it was stable, the load of bacteria was found clearly augmented in the colon and caecum from C3 deficient mice. The extent of Listeria accumulation was indeed comparable to that observed in mice with ATG7 deficiency restricted to intestinal epithelial cells. Also of interest was the observation that despite an unperturbed level of ATG16L1, the expression level of both LC3 and ATG7 core autophagy factors was lowered after Listeria infection, indicating that the autophagy machinery was perturbed in C3-deficient mice. The bacterial burden seen in C3 deficient mice could be brought back to the level of that seen in normal mice by simply administrating the autophagy activator rapamycin to animals confirming that the anti-Listeria autophagic response of C3 deficient intestinal cells was readily altered. Hence, C3 is efficient at enhancing the anti-Listeria autophagic response in the intestine of infected mice. Besides the C3-ATG16L1 interaction, this contribution might involve a transcriptional modulation of the LC3 and Atg7 genes and perhaps, other factors that remain to be examined.

Interestingly, endogenously produced cytosolic C3 is also capable of influencing autophagy through interaction with ATG16L1. For instance, human pancreatic beta cells were shown to produce C3 that positively regulates autophagy via its interaction with ATG16L1 thereby contributing to cell homeostasis and stress resistance [87]. The endogenously produced intracellular C3 corresponds to its precursor form as it does not access the classical secretory pathway. As a consequence, the intracellular C3-ATG16L1 interaction appears to require neither $\mathrm{C} 3$ glycosylation nor the production of the processed form of $C 3$ (the $\alpha / \beta$ two chains form of (3). Whether the cytosolic environment of mammalian cells contains C3-convertase-like activity able to generate $\mathrm{C} 3 \mathrm{~b}$ that could deposit onto invading bacteria and enhance anti-bacterial autophagy as in the case of C3coated Listeria is unknown. Collectively, the available results suggest that the C3-ATG16L1 interaction is capable of modulating autophagy not only at the initiation step but also at the level of autophagosome maturation. How these modulations take place and the detail of their regulation in various cell types remain to be investigated. Of interest is the fact that unlike the ATG16L1-native C3 interaction, the interaction of ATG16L1 with cleavage-products of C3 (C3b, iC3b, C3d, C3c) is very poor in vitro [87]. Hence, the cleavage of intracellular $\mathrm{C} 3$ by endogenous enzymes could possibly represent a mean to adjust the effects of the C3ATG16L1 interaction. Pools of cytosolic C3 can be observed within several cell types such as cells of the immune system, fibroblasts epithelial cells and endothelial cells. The production of cytosolic $\mathrm{C} 3$, the conditions involved in the formation of $\mathrm{C} 3$ stores and the requirement for their persistence in distinct cell types remain to be fully characterized. Within CD4 T lymphocytes, it was noticed that the hydrolase cathepsin L is able to cleave $\mathrm{C} 3$ in order to generate C3a that positively regulate cell persistence through tonic activation of mTOR. Whether regulation of the autophagy pathway contributes to this pro-survival outcome deserves further investigation.

\section{THE ANCIENT IMMUNE SIGNALING PATHWAY} Mcr/Draper MODULATES AUTOPHAGY IN DROSOPHILA During Drosophila melanogaster development, hormones promote cell death in certain organs such as larval salivary glands. During this phase, active caspases and autophagic activity are both involved in the disposal of cell debris [88]. Studying the regulation of autophagy during this process, Lin et al., [89] examined a possible role for Draper, an ancient immune receptor that is a member of the epidermal growth factor (EGF)-like-repeat-containing receptor family 
and a $D$. melanogaster orthologue of cell death abnormality protein-1 (CED-1) in Caenorhabditis elegans. Draper contains an intracellular portion that signals for phagocytosis in response to altered self $[90,91]$, is known to act upstream of genes of the autophagy machinery and is required for autophagy associated with the developmental remodeling of salivary glands [92]. Indeed, the external portion of Draper turned out to be mandatory for salivary gland remodeling suggesting that an extracellular cue is able to activate Draper-activated autophagy. With this respect, a role for macroglobulin complement-related (Mcr/TEPVI), a factor related to the thioester-containing protein family, was investigated because its expression is detected in salivary glands and its level increases in the presence of ecdysone. Mcr is among the best-described complement-like opsonins in $D$. melanogaster where it represents an important defense factor against Candida albicans infection [93]. Lin et al. found that mor invalidation in salivary glands caused the aggregation of vacuolated cellular fragments that closely resembled those observed upon autophagy blockade via Atg13 knockdown. Enforcing autophagy via Atg1 overexpression could compensate for such a degradation defect, pointing to an important role for Mcr upstream of Atg1 in the autophagy process involved in salivary gland cell disposal. Mcr is in fact mandatory for salivary gland-associated autophagy as shown by the scarcity of Atg8a punctiform structures and an increased level of $\operatorname{Ref}(2) \mathrm{P}$, the $D$. melanogaster ortholog of p62/SQSTM1, in salivary glands lacking Mcr. Remarkably, exogenous Mcr is capable of influencing the formation of Atg8a-positive puncta in wild type and Mcr deficient cells to a similar extend, indicating that Mcr can regulate autophagy in a non-cell autonomous manner. In vivo, the cumulative mutations of $\mathrm{mcr}$ and draper caused a more marked degradation defect than either mutation considered individually. This phenotype was associated with a rarefaction of Atg8 puncta and reverted upon Atg1 ectopic expression. Of interest was the fact that a constitutively active version of Src42A, the enzyme responsible for Draper phosphorylation and that is required for degradative activity during salivary gland development, could compensate for the defect imposed by Mcr deficiency. Hence, Mcr functions upstream of draper to signal for autophagy induction. In D. melanogaster embryo, the Draper-Src42A module also participates in macrophage migration to damaged epithelium (Fig. 2A). In the absence of Mcr, the migration of macrophages is reduced and most of them display a low level of Atg8a puncta formation because epithelial cell production of Mcr along with Draper expression by macrophages, are necessary for autophagy induction. The exogenous provision of $\mathrm{Mcr}$ is sufficient to activate autophagy in embryonic macrophages in vitro in a Draper and Atg1/3/5 dependent manner. Thus, in $D$. melanogaster, interaction of the complement-like opsonin Mcr with the EGF-like-repeat-containing receptor Draper can mobilize the autophagy machinery in a non-cell autonomous fashion. This pathway is instrumental for the regulatory role of autophagy both in the remodeling of salivary gland during development and in macrophages involved in the resolu- tion of epithelial cell death in the embryo. The productive engagement of Draper by Mcr for phagocytosis induction and the known role of $\mathrm{Mcr}$ in immune response to fungi [93] and flaviviruses [94] in insects suggest an ancient origin for the Mcr-Draper axis. The observations by Lin et al. [89] now reveal that this ancient immune signaling axis can function in the regulation of autophagy in the remodeling of tissues during development (Fig. 2B). Phylogenetically, it would be interesting to determine whether Multiple EGFlike domain Factor 10 (MEGF10), a mammalian factor related to Draper and serves as a receptor for the C1q complement factor [95] can be connected to autophagy induction pathways.

\section{CONCLUDING REMARKS}

A substantial corpus of recent observations indicates that besides their immune functions, complement system factors can regulate various cellular functions in both physiological and pathological settings. Factors of the complement system are indeed capable of directly promoting autophagic activity. For instance, cell surface receptors belonging to the complement system have the capacity to trigger anti-bacterial autophagy response as illustrated by the human complement regulatory factor CD46 that induces a marked burst of autophagy in epithelial cells in response to virus/bacteria sensing. In that case, autophagy induction relies on the CD46-Cyt1 isoform that recruits the GOPC factor leading to engagement of the VPS34-BECLIN1 complex. While CD46 interacts on an in cis mode when engaged in the neutralization of $\mathrm{C} 3 \mathrm{~b}$, the VSIG4 receptor binds to $\mathrm{C} 3 \mathrm{~b}$ in trans to facilitate the endocytosis of C3bcoated Listeria by phagocytes. Although the detailed intermediate steps and factors involved remain to be identified, it is established that VSIG4-mediated activation of autophagy also involves the recruitment of BECLIN1.

A link between activation of the autophagy machinery and engagement of complement-related factors can also be observed in insects. Mcr, a drosophila factor related to C3, can initiate autophagy in epithelial cells of the developing salivary gland in both an autocrine and paracrine manner to regulate the homeostasis of the tissue. Via modulation of autophagy, Mcr can also regulate the migration of phagocytic cells to inflammatory sites during embryogenesis. Autophagy activation by Mcr involves the ancient microbe-sensing axis called the Draper-Src42A pathway. The mammalian ortholog of Draper is MEGF10 that is capable of interacting with $\mathrm{C} 1 \mathrm{q}$. Hence it would be interesting to examine whether the C1q-MEGF10 interaction can influence developmental processes and/or immune responses to microbial infection in mammalian cells via autophagy induction/modulation. Indeed, a modulatory effect of C1q on epithelial cell autophagy has been reported. It involves the interaction of $\mathrm{C} 1 \mathrm{q}$ with the metalloproteinase ADAM 28 and disintegrin and appears to influence susceptibility to cell death [96]. It remains to be investigated whether other membrane-associated complement factors or complement factors interacting with surface receptors are able to regulate autophagy. In addition, it will be interesting to examine to which extend pathogens may have evolved 
A

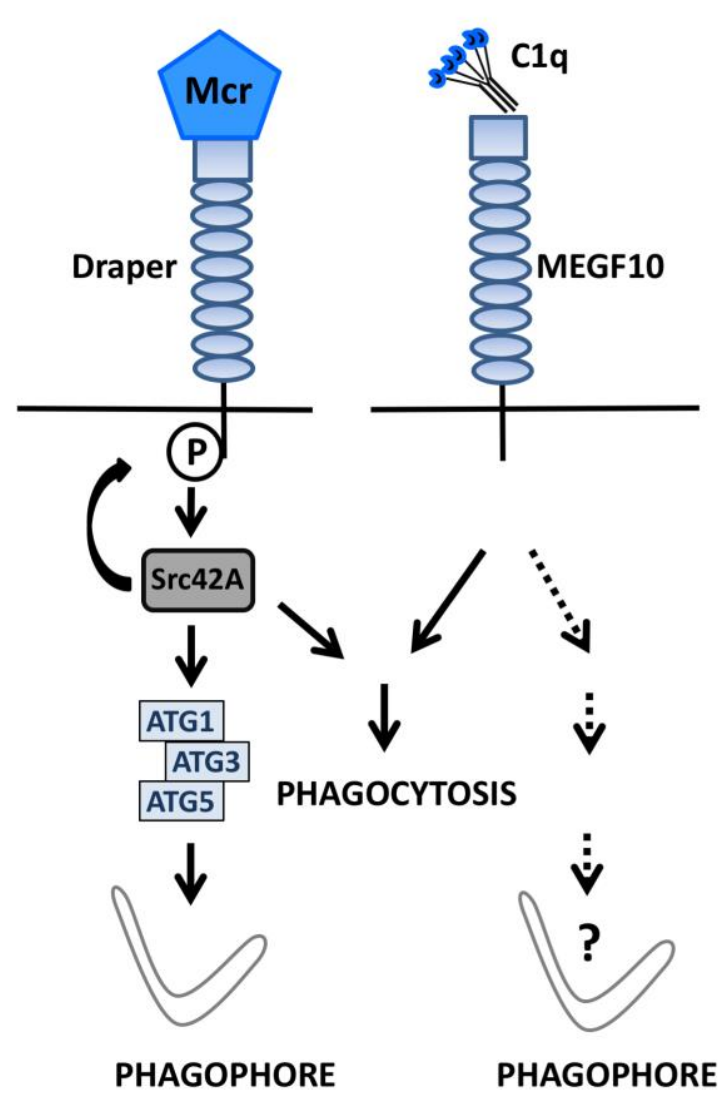

B

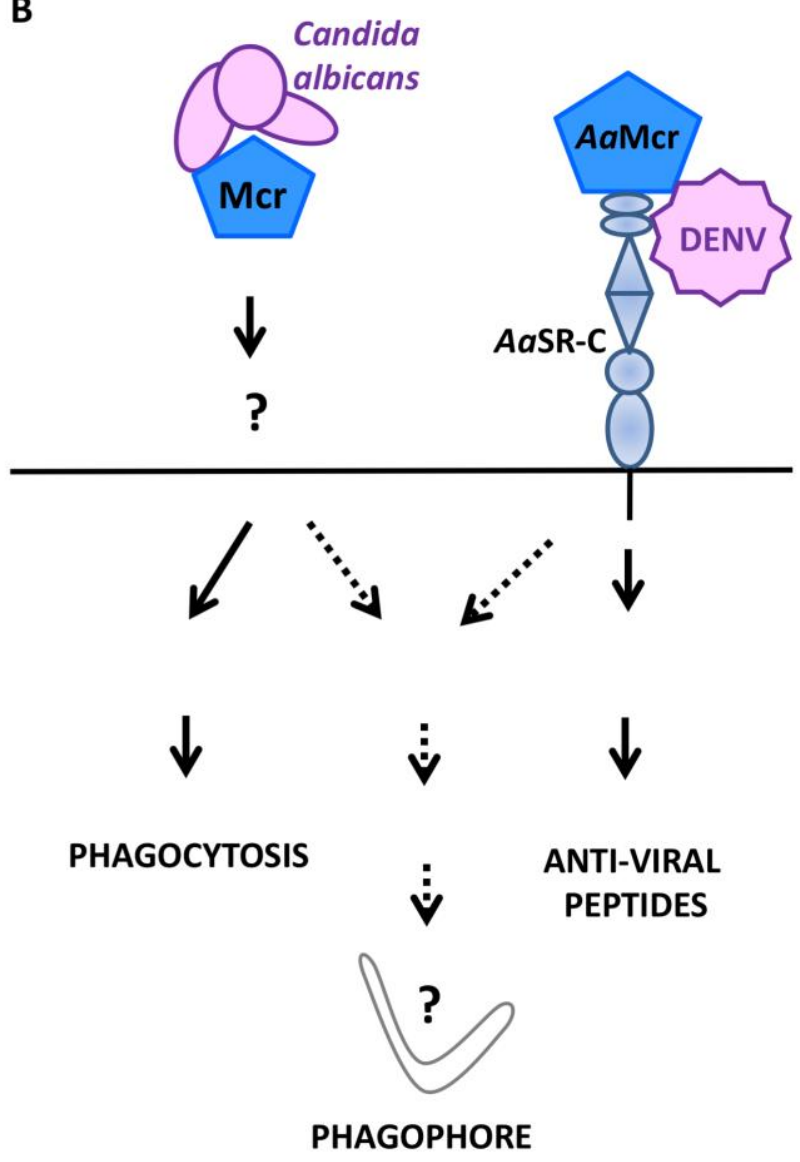

FIGURE 2: Macroglobulin complement related factor (Mcr) in antimicrobial defense and autophagy. (A) During D. melanogaster development, the complement-like opsonin Macroglobulin complement related/TEPVI (Mcr), that is highly similar to mammalian complement factor C3, can initiate autophagy in both epithelial cells and macrophages by engaging Draper, a Src42A protein kinase-coupled, EGF-likerepeat-containing receptor known to signal for phagocytosis (left). Whether Multiple EGF-like-domain Factor 10 (MEGF10), a mammalian ortholog of Draper that mediates phagocytosis in response to C1q binding, can also signal for autophagy induction is unknown (right). (B) Mcr mediates the selective phagocytosis of Candida albicans in D. melanogaster (left) and, along with the scavenger receptor-C (AaSR-C) is involved in initiating the production of anti-viral peptides in response to the Dengue virus (DENV) in Aedes aegypti (AaMcr)(right). Whether pathogen sensing by $\mathrm{Mcr}$ (with a role for Draper in the case of $D$. melanogaster?) can activate anti-microbial autophagy in insects remains to be studied.

means to oppose/ escape, autophagy induction by components of the complement system.

A truly unanticipated finding was the capacity of $\mathrm{C} 3$ deposited onto bacteria to promote anti-bacterial autophagy via direct interaction with the core autophagy factor ATG16L1 after internalization. This enhancing effect on autophagy translated into an ameliorated restriction of bacteria as demonstrated by the altered response to Listeria infection in mice lacking C3. Of note, hydrolytic reactions that degrade C3 deposition on some bacteria allow them to escape the enhancing effect of the C3-ATG16L1 interaction on anti-bacterial autophagy. With respect to the cytosolic C3-ATG16L1 interaction and its role in antimicrobial autophagy, it remains to be determined whether endogenously produced C3 than can operate in maintaining homeostasis of cells such as pancreatic beta cells, can get adsorbed onto invading cytosolic bacteria and promote their restriction by the autophagy machinery. Retrospectively, it would be also interesting to determine whether C3 deposited on viruses such as adenovirus [59] can activate autophagy via ATG16L1 engagement once it exited the endocytic vacuole.

Among questions raised by the observation that factors of the complement system can regulate the autophagic activity is the issue of whether autophagy itself can in turn regulate the intracellular functions of complement factors. Possibly, the autophagy machinery could regulate the intracellular function of complement factors at large via their specific degradation or via degradation of factors necessary for their production in the case of complement factors produced intracellularly. Such regulatory effect would be somehow reminiscent of that involved in the regulation of the inflammasome by the autophagy machinery [97]. Finally, it remains also to be studied whether complement fac- 
tors present intracellularly can interact with either a restricted or a larger set of the core factors involved in the autophagy flux and what are the functional consequences both at steady state and under conditions of infection.

Multiple observations now indicate that factors of the complement system mediate intracellular functions. It has been suggested that such phenomena could represent the manifestation of a cell-intrinsic complement system for which the term of "complosome" has been coined. As evoked above, one may ask whether such intracellular functions indeed co-evolved with the extracellular functions of the complement system or whether they could have even preceded it $[98,63,58]$. Regardless of the right answer, it seems fair to state that the relationship between autophagy and factors of the complement system, as well as the impact of this relationship on the defense against microbes, are very likely to have emerged early during evolution.

\section{ACKNOWLEDGMENTS}

Our team is supported by la Fondation pour la Recherche Médicale (Label Equipe FRM), the French National Research Agency (ANR-11-IDEX-0007), I'Association François Aupetit (AFA) and the French Society of Gastroenterogists (SNFGE).

\section{CONFLICT OF INTEREST \\ We report no conflict of interest.}

\section{COPYRIGHT}

(C) 2020 Viret et al. This is an open-access article released under the terms of the Creative Commons Attribution (CC BY) license, which allows the unrestricted use, distribution, and reproduction in any medium, provided the original author and source are acknowledged.

Please cite this article as: Christophe Viret, Aurore Rozières, Rémi Duclaux-Loras, Gilles Boschetti, Stéphane Nancey and Mathias Faure (2020). Regulation of anti-microbial autophagy by factors of the complement system. Microbial Cell 7(4): 93-105. doi: 10.15698/mic2020.04.712

\section{REFERENCES}

1. Codogno $P$, and Meijer AJ (2005). Autophagy and signaling: their role in cell survival and cell death. Cell Death Differ 12: 1509-1518. doi: $10.1038 /$ sj.cdd.4401751

2. Boya $P$, Reggiori $F$, and Codogno $P$ (2013). Emerging regulation and functions of autophagy. Nat Cell Biol 15(7): 713-720. doi: $10.1038 /$ ncb2788

3. Levine B, and Kroemer G (2008). Autophagy in the Pathogenesis of Disease. Cell 132(1): 27-42. doi: 10.1016/j.cell.2007.12.018

4. Levine B (2005). Eating Oneself and Uninvited Guests. Cell 120(2): 159-162. doi: 10.1016/j.cell.2005.01.005

5. Sorbara MT, and Girardin SE (2015). Emerging themes in bacterial autophagy. Curr Opin Microbiol 23: 163-170. doi: 10.1016/j.mib.2014.11.020

6. Wu Y-W, and Li F (2019). Bacterial interaction with host autophagy. Virulence 10(1): 352-362. 30978154

7. Sharma V, Verma S, Seranova E, Sarkar S, and Kumar D (2018). Selective Autophagy and Xenophagy in Infection and Disease. Front Cell Dev Biol 6: 147. doi: 10.3389/fcell.2018.00147

8. Jordan TX, and Randall G (2012). Manipulation or capitulation: virus interactions with autophagy. Microbes Infect 14(2): 126-139. doi: 10.1016/j.micinf.2011.09.007

9. Dong X, and Levine B (2013). Autophagy and Viruses: Adversaries or Allies? J Innate Immun 5(5): 480-493. doi: 10.1159/000346388

10. Paul P, and Münz C (2016). Autophagy and Mammalian Viruses: Roles in Immune Response, Viral Replication, and Beyond. Adv Virus Res 95:149-195. doi: 10.1016/bs.aivir.2016.02.002

11. Shelly S, Lukinova N, Bambina S, Berman A, and Cherry S (2009). Autophagy Is an Essential Component of Drosophila Immunity against Vesicular Stomatitis Virus. Immunity 30(4): 588-598. doi: 10.1016/j.immuni.2009.02.009

12. Orvedahl A, MacPherson S, Sumpter R, Tallóczy Z, Zou Z, and Levine $B(2010)$. Autophagy Protects against Sindbis Virus Infection of the
Central Nervous System. Cell Host Microbe 7(2): 115-127. doi: 10.1016/j.chom.2010.01.007

13. Lee HK, Mattei LM, Steinberg BE, Alberts P, Lee YH, Chervonsky A, Mizushima N, Grinstein S, and Iwasaki A (2010). In Vivo Requirement for Atg5 in Antigen Presentation by Dendritic Cells. Immunity 32(2): 227-239. doi: 10.1016/j.immuni.2009.12.006

14. Viret $C$, Rozières $A$, and Faure $M$ (2018). Autophagy during Early Virus-Host Cell Interactions. J Mol Biol 430(12): 1696-1713. doi 10.1016/j.jmb.2018.04.018

15. Criollo A, Senovilla L, Authier H, Maiuri MC, Morselli E, Vitale I, Kepp O, Tasdemir E, Galluzzi L, Shen S, Tailler M, Delahaye N, Tesniere A, De Stefano D, Younes AB, Harper F, Pierron G, Lavandero S, Zitvogel L, Israel A, Baud V, and Kroemer G (2010). The IKK complex contributes to the induction of autophagy. EMBO J 29(3): 619-631. doi: 10.1038/emboj.2009.364

16. Watson RO, Bell SL, MacDuff DA, Kimmey JM, Diner EJ, Olivas J, Vance RE, Stallings CL, Virgin HW, and Cox JS (2015). The Cytosolic Sensor cGAS Detects Mycobacterium tuberculosis DNA to Induce Type I Interferons and Activate Autophagy. Cell Host Microbe 17(6): 811819. doi: 10.1016/j.chom.2015.05.004

17. Antonioli M, Di Rienzo M, Piacentini M, and Fimia GM (2017). Emerging Mechanisms in Initiating and Terminating Autophagy. Trends Biochem Sci 42(1): 28-41. doi: 10.1016/j.tibs.2016.09.008

18. Pietrocola F, Izzo V, Niso-Santano M, Vacchelli E, Galluzzi L, Maiuri responsive transcription factors. Semin Cancer Biol 23(5): 310-322. doi: 10.1016/j.semcancer.2013.05.008

19. He C, and Klionsky DJ (2009). Regulation Mechanisms and Signaling Pathways of Autophagy. Annu Rev Genet 43(1): 67-93. doi: 10.1146/annurev-genet-102808-114910

20. Yin Z, Pascual C, and Klionsky D (2016). Autophagy: machinery and regulation. Microbial Cell 3(12): 588-596. doi: 10.15698/mic2016.12.546 $\mathrm{MC}$, and Kroemer $\mathrm{G}$ (2013). Regulation of autophagy by stress- 
21. Ktistakis NT, and Tooze SA (2016). Digesting the Expanding Mechanisms of Autophagy. Trends Cell Biol 26(8): 624-635. doi: 10.1016/j.tcb.2016.03.006

22. Bento CF, Renna M, Ghislat G, Puri C, Ashkenazi A, Vicinanza M, Menzies FM, and Rubinsztein DC (2016). Mammalian Autophagy: How Does It Work? Annu Rev Biochem 85(1): 685-713. doi: 10.1146/annurev-biochem-060815-014556

23. Xie Z, and Klionsky DJ (2007). Autophagosome formation: core machinery and adaptations. Nat Cell Biol 9(10): 1102-1109. doi: 10.1038/ncb1007-1102

24. Shen H-M, and Mizushima N (2014). At the end of the autophagic road: an emerging understanding of lysosomal functions in autophagy. Trends Biochem Sci 39(2): 61-71. doi: 10.1016/j.tibs.2013.12.001

25. Yu S, and Melia TJ (2017). The coordination of membrane fission and fusion at the end of autophagosome maturation. Curr Opin Cell Biol 47: 92-98. doi: 10.1016/j.ceb.2017.03.010

26. Stolz A, Ernst A, and Dikic I (2014). Cargo recognition and trafficking in selective autophagy. Nat Cell Biol 16(6): 495-501. doi: $10.1038 /$ ncb2979

27. Rogov V, Dötsch V, Johansen $T$, and Kirkin V (2014). Interactions between Autophagy Receptors and Ubiquitin-like Proteins Form the Molecular Basis for Selective Autophagy. Mol Cell 53(2): 167-178. doi: 10.1016/j.molcel.2013.12.014

28. Verlhac $P$, Grégoire IP, Azocar O, Petkova DS, Baguet J, Viret C, and Faure M (2015). Autophagy Receptor NDP52 Regulates PathogenContaining Autophagosome Maturation. Cell Host Microbe 17(4): 515-525. doi: 10.1016/j.chom.2015.02.008

29. Tumbarello DA, Manna PT, Allen M, Bycroft M, Arden SD, Kendrick-Jones J, and Buss F (2015). The Autophagy Receptor TAX1BP1 and the Molecular Motor Myosin VI Are Required for Clearance of Salmonella Typhimurium by Autophagy. PLOS Pathog 11(10): e1005174. doi: 10.1371/journal.ppat.1005174

30. Petkova $D$, Verlhac $P$, Rozières $A$, Baguet J, Claviere $M$, Kretz-Remy C, Mahieux R, Viret C, and Faure M (2017). Distinct Contributions of Autophagy Receptors in Measles Virus Replication. Viruses 9(5): 123. doi: 10.3390/v9050123

31. Gros P, Milder FJ, and Janssen BJC (2008). Complement driven by conformational changes. Nat Rev Immunol 8(1): 48-58. doi: 10.1038/nri2231

32. Carroll MC (2004). The complement system in regulation of adaptive immunity. Nat Immunol 5(10): 981-986. doi: 10.1038/ni1113

33. Reis ES, Mastellos DC, Hajishengallis G, and Lambris JD (2019). New insights into the immune functions of complement. Nat Rev Immunol 19(8): 503-516. doi: 10.1038/s41577-019-0168-X

34. Erdei A, Sándor N, Mácsik-Valent B, Lukácsi S, Kremlitzka M, and Bajtay $Z$ (2016). The versatile functions of complement C3-derived ligands. Immunol Rev 274(1): 127-140. doi: 10.1111/imr.12498

35. Zhu Y, Thangamani S, Ho B, and Ding JL (2005). The ancient origin of the complement system. EMBO J 24(2): 382-394. doi: 10.1038/sj.emboj.7600533

36. Walport MJ (2001). Complement. N Engl J Med 344(14): 10581066. doi: 10.1056/NEJM200104053441406

37. Bajic G, Degn SE, Thiel S, and Andersen GR (2015). Complement activation, regulation, and molecular basis for complement-related diseases. EMBO J 34(22): 2735-2757. doi: 10.15252/embj.201591881

38. Pangburn MK (1981). Formation of the initial C3 convertase of the alternative complement pathway. Acquisition of C3b-like activities by spontaneous hydrolysis of the putative thioester in native C3. J Exp Med 154(3): 856-867. doi: 10.1084/jem.154.3.856
39. Fearon DT (1973). Formation of a hemolytically active cellular intermediate by the interaction between properdin factors $B$ and $D$ and the activated third component of complement. J Exp Med 138(6): 1305-1313. doi: 10.1084/jem.138.6.1305

40. Law SKA, and Dodds AW (2008). The internal thioester and the covalent binding properties of the complement proteins $\mathrm{C} 3$ and $\mathrm{C} 4$ Protein Sci 6(2): 263-274. doi: 10.1002/pro.5560060201

41. Müller-Eberhard HJ, Polley MJ, and Calcott MA (1967). Formation and functional significance of a molecular complex derived from the second and the fourth component of human complement. J Exp Med 125(2): 359-380. doi: 10.1084/jem.125.2.359

42. Kjaer TR, Thiel S, and Andersen GR (2013). Toward a structurebased comprehension of the lectin pathway of complement. Mol Immunol 56(4): 413-422. doi: 10.1016/j.molimm.2013.05.007

43. Henriksen ML, Brandt J, Andrieu J-P, Nielsen $C$, Jensen $P H$, Holmskov $U$, Jorgensen TJD, Palarasah $Y$, Thielens NM, and Hansen $S$ (2013). Heteromeric Complexes of Native Collectin Kidney 1 and Collectin Liver 1 Are Found in the Circulation with MASPs and Activate the Complement System. J Immunol 191(12): 6117-6127. doi: 10.4049/jimmunol.1302121

44. Matsushita M, Thiel S, Jensenius JC, Terai I, and Fujita T (2000). Proteolytic Activities of Two Types of Mannose-Binding LectinAssociated Serine Protease. J Immunol 165(5): 2637-2642. doi: 10.4049/jimmunol.165.5.2637

45. Rossi V, Cseh S, Bally I, Thielens NM, Jensenius JC, and Arlaud GJ (2001). Substrate Specificities of Recombinant Mannan-binding Lectinassociated Serine Proteases-1 and -2. J Biol Chem 276(44): 4088040887. doi: 10.1074/jbc.M105934200

46. Chen C-B, and Wallis R (2004). Two Mechanisms for Mannosebinding Protein Modulation of the Activity of Its Associated Serine Proteases. J Biol Chem 279(25): 26058-26065. doi: 10.1074/jbc.M401318200

47. Medicus RG (1976). Alternative pathway of complement: recruitment of precursor properdin by the labile $\mathrm{C} 3 / \mathrm{C} 5$ convertase and the potentiation of the pathway. J Exp Med 144(4): 1076-1093. doi: 10.1084/jem.144.4.1076

48. Takata Y (1987). Covalent association of C3b with C4b within C5 convertase of the classical complement pathway. J Exp Med 165(6): 1494-1507. doi: 10.1084/jem.165.6.1494

49. Bubeck D (2014). The Making of a Macromolecular Machine: Assembly of the Membrane Attack Complex. Biochemistry 53(12): 19081915. doi: 10.1021/bi500157z

50. Klos A, Tenner AJ, Johswich K-O, Ager RR, Reis ES, and Köhl J (2009). The role of the anaphylatoxins in health and disease. Mol Immunol 46(14): 2753-2766. doi: 10.1016/j.molimm.2009.04.027

51. Guo R-F, and Ward PA (2005). Role of c5a in inflammatory responses. Annu Rev Immunol 23(1): 821-852. doi: 10.1146/annurev.immunol.23.021704.115835

52. Hourcade D, Holers VM, and Atkinson JP (1989). The regulators of complement activation (RCA) gene cluster. Adv Immunol 45: 381-416. doi: 10.1016/s0065-2776(08)60697-5

53. Zipfel PF, and Skerka C (2009). Complement regulators and inhibitory proteins. Nat Rev Immunol 9(10): 729-740. doi: 10.1038/nri2620

54. Lambris JD, Ricklin D, and Geisbrecht BV (2008). Complement evasion by human pathogens. Nat Rev Microbiol 6(2): 132-142. doi: 10.1038/nrmicro1824

55. Hajishengallis G, Reis ES, Mastellos DC, Ricklin D, and Lambris JD (2017). Novel mechanisms and functions of complement. Nat Immunol 18(12): 1288-1298. doi: 10.1038/ni.3858 
56. Arbore G, West EE, Spolski R, Robertson AAB, Klos A, Rheinheimer C, Dutow P, Woodruff TM, Yu ZX, ONeill LA, Coll RC, Sher A, Leonard WJ, Kohl J, Monk P, Cooper MA, Arno M, Afzali B, Lachmann HJ, Cope $A P$, Mayer-Barber KD, and Kemper $C$ (2016). T helper 1 immunity requires complement-driven NLRP3 inflammasome activity in CD4+ T cells. Science 352(6292): aad1210-aad1210. doi: 10.1126/science.aad1210

57. Liszewski MK, Kolev M, Le Friec G, Leung M, Bertram PG, Fara AF, Subias M, Pickering MC, Drouet C, Meri S, Arstila TP, Pekkarinen PT, Ma M, Cope A, Reinheckel T, Rodriguez de Cordoba S, Afzali B, Atkinson JP, and Kemper C (2013). Intracellular Complement Activation Sustains T Cell Homeostasis and Mediates Effector Differentiation. Immunity 39(6): 1143-1157. doi: 10.1016/j.immuni.2013.10.018

58. Kolev M, and Kemper C (2017). Keeping It All Going-Complement Meets Metabolism. Front Immunol 8: 1. doi: 10.3389/fimmu.2017.00001

59. Tam JCH, Bidgood SR, McEwan WA, and James LC (2014). Intracellular sensing of complement C3 activates cell autonomous immunity. Science 345(6201): 1256070-1256070. doi: 10.1126/science.1256070

60. Lambris JD (1980). Release of endogenous C3b inactivator from lymphocytes in response to triggering membrane receptors for beta $1 \mathrm{H}$ globulin. J Exp Med 152(6): 1625-1644. doi: 10.1084/jem.152.6.1625

61. Elvington M, Liszewski MK, Bertram P, Kulkarni HS, and Atkinson JP (2017). A C3(H20) recycling pathway is a component of the intracellular complement system. J Clin Invest 127(3): 970-981. doi: $10.1172 / \mathrm{JCl} 89412$

62. Freeley S, Kemper C, and Le Friec G (2016). The "ins and outs" of complement-driven immune responses. Immunol Rev 274(1): 16-32. doi: $10.1111 /$ imr.12472

63. Liszewski MK, Elvington M, Kulkarni HS, and Atkinson JP (2017). Complement's hidden arsenal: New insights and novel functions inside the cell. Mol Immunol 84: 2-9. doi: 10.1016/j.molimm.2017.01.004

64. Kolev M, Dimeloe S, Le Friec G, Navarini A, Arbore G, Povoleri GA, Fischer M, Belle R, Loeliger J, Develioglu L, Bantug GR, Watson J, Couzi L, Afzali B, Lavender P, Hess C, and Kemper C (2015). Complement Regulates Nutrient Influx and Metabolic Reprogramming during Th1 Cell Responses. Immunity 42(6): 1033-1047. doi: 10.1016/j.immuni.2015.05.024

65. Naniche D, Varior-Krishnan G, Cervoni F, Wild TF, Rossi B, Rabourdin-Combe C, and Gerlier D (1993). Human membrane cofactor protein (CD46) acts as a cellular receptor for measles virus. J Virol 67(10): 6025-6032. doi: 10.1128/jvi.67.10.6025-6032.1993

66. Riley-Vargas RC, Gill DB, Kemper C, Liszewski MK, and Atkinson JP (2004). CD46: expanding beyond complement regulation. Trends Immunol 25(9): 496-503. doi: 10.1016/j.it.2004.07.004

67. Yamamoto H, Fara AF, Dasgupta P, and Kemper C (2013). CD46: The "multitasker" of complement proteins. Int J Biochem Cell Biol 45(12): 2808-2820. doi: 10.1016/j.biocel.2013.09.016

68. Joubert P-E, Meiffren G, Grégoire IP, Pontini G, Richetta C, Flacher M, Azocar O, Vidalain P-O, Vidal M, Lotteau V, Codogno P, RabourdinCombe $C$, and Faure $\mathrm{M}$ (2009). Autophagy induction by the pathogen receptor CD46. Cell Host Microbe 6(4): 354-366. doi: 10.1016/j.chom.2009.09.006

69. Purcell DFJ, Russell SM, Deacon NJ, Brown MA, Hooker DJ, and McKenzie IFC (1991). Alternatively spliced RNAs encode several isoforms of CD46 (MCP), a regulator of complement activation. Immunogenetics 33(5-6): 335-344. doi: 10.1007/BF00216692

70. Richetta C, Grégoire IP, Verlhac P, Azocar O, Baguet J, Flacher M, Tangy F, Rabourdin-Combe C, and Faure M (2013). Sustained Autoph- agy Contributes to Measles Virus Infectivity. PLoS Pathog 9(9): e1003599. doi: 10.1371/journal.ppat.1003599

71. Rozières A, Viret $C$, and Faure $M$ (2017). Autophagy in Measles Virus Infection. Viruses 9(12): 359. doi: 10.3390/v9120359

72. Kim WJ, Mai A, Weyand NJ, Rendón MA, Van Doorslaer K, and So $M$ (2019). Neisseria gonorrhoeae evades autophagic killing by downregulating CD46-cyt1 and remodeling lysosomes. PLOS Pathog 15(2): e1007495. doi: 10.1371/journal.ppat.1007495

73. Cattaneo R (2004). Four viruses, two bacteria, and one receptor: membrane cofactor protein (CD46) as pathogens' magnet. J Virol 78(9): 4385-4388. doi: 10.1128/jvi.78.9.4385-4388.2004

74. Helmy KY, Katschke KJ, Gorgani NN, Kljavin NM, Elliott JM, Diehl L, Scales SJ, Ghilardi N, and van Lookeren Campagne M (2006). CRIg: A Macrophage Complement Receptor Required for Phagocytosis of Circulating Pathogens. Cell 124(5): 915-927. doi 10.1016/j.cell.2005.12.039

75. Kim J-K, Choi EM, Shin H-I, Kim CH, Hwang S-H, Kim S-M, and Kwon BS (2005). Characterization of monoclonal antibody specific to the Z39lg protein, a member of immunoglobulin superfamily. Immunol Lett 99(2): 153-161. doi: 10.1016/j.imlet.2005.02.012

76. Kim KH, Choi BK, Song KM, Cha KW, Kim YH, Lee H, Han I-S, and Kwon BS (2013). CRIg signals induce anti-intracellular bacterial phagosome activity in a chloride intracellular channel 3-dependent manner: Immunity to infection. Eur J Immunol 43(3): 667-678. doi: 10.1002/eji.201242997

77. Kim KH, Choi BK, Kim YH, Han C, Oh HS, Lee DG, and Kwon BS (2016). Extracellular stimulation of VSIG4/complement receptor Ig suppresses intracellular bacterial infection by inducing autophagy. Autophagy 12(9): 1647-1659. doi: 10.1080/15548627.2016.1196314

78. Sorbara MT, Foerster EG, Tsalikis J, Abdel-Nour M, Mangiapane J, Sirluck-Schroeder I, Tattoli I, van Dalen R, Isenman DE, Rohde JR, Girardin SE, and Philpott DJ (2018). Complement C3 Drives AutophagyDependent Restriction of Cyto-invasive Bacteria. Cell Host Microbe 23(5): 644-652.e5. doi: 10.1016/j.chom.2018.04.008

79. Hampe J, Franke A, Rosenstiel P, Till A, Teuber M, Huse K, Albrecht M, Mayr G, De La Vega FM, Briggs J, Günther S, Prescott NJ, Onnie CM, Häsler R, Sipos B, Fölsch UR, Lengauer T, Platzer M, Mathew CG, Krawczak M, and Schreiber S (2007). A genome-wide association scan of nonsynonymous SNPs identifies a susceptibility variant for Crohn disease in ATG16L1. Nat Genet 39(2): 207-211. doi: 10.1038/ng1954

80. Darfeuille-Michaud A, Boudeau J, Bulois P, Neut C, Glasser A-L, Barnich N, Bringer M-A, Swidsinski A, Beaugerie L, and Colombel J-F (2004). High prevalence of adherent-invasive Escherichia coli associated with ileal mucosa in Crohn's disease. Gastroenterology 127(2): 412-421. doi: 10.1053/j.gastro.2004.04.061

81. Lapaquette P, Glasser A-L, Huett A, Xavier RJ, and DarfeuilleMichaud A (2010). Crohn's disease-associated adherent-invasive $E$. coli are selectively favoured by impaired autophagy to replicate intracellularly. Cell Microbiol 12(1): 99-113. doi: 10.1111/j.14625822.2009.01381.x

82. Hritonenko V, and Stathopoulos C (2007). Omptin proteins: an expanding family of outer membrane proteases in Gram-negative Enterobacteriaceae (Review). Mol Membr Biol 24(5-6): 395-406. doi: 10.1080/09687680701443822

83. Shere KD, Sallustio S, Manessis A, D’Aversa TG, and Goldberg MB (1997). Disruption of IcsP, the major Shigella protease that cleaves IcsA, accelerates actin-based motility. Mol Microbiol 25(3): 451-462. doi: 10.1046/j.1365-2958.1997.4681827.x

84. Ramu P, Tanskanen R, Holmberg M, Lähteenmäki K, Korhonen TK, and Meri S (2007). The surface protease PgtE of Salmonella enterica 
affects complement activity by proteolytically cleaving C3b, C4b and C5. FEBS Lett 581(9): 1716-1720. doi: 10.1016/j.febslet.2007.03.049

85. Riva R, Korhonen TK, and Meri S (2015). The outer membrane protease PgtE of Salmonella enterica interferes with the alternative complement pathway by cleaving factors B and H. Front Microbiol 6 : 63. doi: $10.3389 /$ fmicb. 2015.00063

86. Wollert T, Pasche B, Rochon M, Deppenmeier S, van den Heuvel J, Gruber AD, Heinz DW, Lengeling A, and Schubert W-D (2007). Extending the Host Range of Listeria monocytogenes by Rational Protein Design. Cell 129(5): 891-902. doi: 10.1016/j.cell.2007.03.049

87. King BC, Kulak K, Krus U, Rosberg R, Golec E, Wozniak K, Gomez MF, Zhang E, O'Connell DJ, Renström E, and Blom AM (2019). Complement Component C3 Is Highly Expressed in Human Pancreatic Islets and Prevents $\beta$ Cell Death via ATG16L1 Interaction and Autophagy Regulation. Cell Metab 29(1): 202-210.e6. doi: 10.1016/j.cmet.2018.09.009

88. Berry DL, and Baehrecke EH (2007). Growth Arrest and Autophagy Are Required for Salivary Gland Cell Degradation in Drosophila. Cell 131(6): 1137-1148. doi: 10.1016/j.cell.2007.10.048

89. Lin L, Rodrigues FSLM, Kary C, Contet A, Logan M, Baxter RHG, Wood W, and Baehrecke EH (2017). Complement-Related Regulates Autophagy in Neighboring Cells. Cell 170(1): 158-171.e8. doi: 10.1016/j.cell.2017.06.018

90. Freeman MR, Delrow J, Kim J, Johnson E, and Doe CQ (2003). Unwrapping Glial Biology. Neuron 38(4): 567-580. doi: 10.1016/S08966273(03)00289-7

91. MacDonald JM, Beach MG, Porpiglia E, Sheehan AE, Watts RJ, and Freeman MR (2006). The Drosophila Cell Corpse Engulfment Receptor
Draper Mediates Glial Clearance of Severed Axons. Neuron 50(6): 869-881. doi: 10.1016/j.neuron.2006.04.028

92. McPhee CK, Logan MA, Freeman MR, and Baehrecke EH (2010). Activation of autophagy during cell death requires the engulfment receptor Draper. Nature 465(7301): 1093-1096. doi: 10.1038/nature09127

93. Stroschein-Stevenson SL, Foley E, O'Farrell PH, and Johnson AD (2005). Identification of Drosophila Gene Products Required for Phagocytosis of Candida albicans. PLoS Biol 4(1): e4. doi: 10.1371/journal.pbio.0040004

94. Xiao X, Liu Y, Zhang X, Wang J, Li Z, Pang X, Wang P, and Cheng G (2014). Complement-Related Proteins Control the Flavivirus Infection of Aedes aegypti by Inducing Antimicrobial Peptides. PLoS Pathog 10(4): e1004027. doi: 10.1371/journal.ppat.1004027

95. Iram T, Ramirez-Ortiz Z, Byrne MH, Coleman UA, Kingery ND, Means TK, Frenkel D, and El Khoury J (2016). Megf10 Is a Receptor for C1Q That Mediates Clearance of Apoptotic Cells by Astrocytes. J Neurosci 36(19): 5185-5192. doi: 10.1523/JNEUROSCI.3850-15.2016

96. Miyamae Y, Mochizuki S, Shimoda M, Ohara K, Abe H, Yamashita S, Kazuno S, Ohtsuka T, Ochiai H, Kitagawa Y, and Okada Y (2016). ADAM 28 is expressed by epithelial cells in human normal tissues and protects from C1q-induced cell death. FEBS J 283(9): 1574-1594. doi: 10.1111/febs.13693

97. Cadwell K (2016). Crosstalk between autophagy and inflammatory signalling pathways: balancing defence and homeostasis. Nat Rev Immunol 16(11): 661-675. doi: 10.1038/nri.2016.100

98. Kolev M, Friec GL, and Kemper C (2014). Complement - tapping into new sites and effector systems. Nat Rev Immunol 14(12): 811820. doi: $10.1038 /$ nri3761 